\title{
Recent Advancements of Augmented Reality in Real Time Applications
}

\author{
Gauri Jha, Pawan Singh, Lavanya Sharma
}

\begin{abstract}
Augmented Reality (AR) is an advanced technology that improves users view of interactivity with the present reality by adding virtual objects in it and it is the most natural way to interface with your digital world. This paper presents a survey about real-time applications, commonly used technologies, various open challenges, possible set of solution provided by several researchers and academicians. This paper also provides future of Augmented reality in various areas of artificial intelligence.
\end{abstract}

Index Terms: Augmented Reality, Virtual reality, Artificial Intelligence, Head mounted display

\section{INTRODUCTION}

The Augmented Reality (AR) is an advanced technology that improves users view of interactivity with the present reality by adding virtual objects in it and it is the most natural way to interface with your digital world. Imagine a world where you look around and wherever you look you see a visualized view that provides information to explain everything and with the help of AR that the world isn't very a big deal [1]. The eventual fate of AR will diverge into two ways: either ordinary use in everyday life or innovative technology that never lift off. Augmented Reality is known as AR and as well as Mixed Reality was like a fiction until it became a science-based reality in the past recent years. Its objective is not to remove you out from the real world and take you to the other one but instead it enhances your real world with 3D virtual objects in it. As the Augmented name itself means "to add" or "to increase", hence AR act as digital addition to the user's world. For example, objects can be displayed on tables, information can be displayed on windows and graphics can generate motion to track the user. In short and brief, it directly affects the perception and thought processes of the human mind [1,2]. It is the only technology that provides the user with an actual based experience like snapchat lenses and the game Pokémon go. Whereas Virtual Reality (VR) is a technology to generate an artificial or imaginative environment like we can explore the places we've never been such as the surface of the moon. AR and VR are two different methods of technologies that can

Revised Manuscript Received on July 5, 2019.

Gauri Jha, Amity Institute of Information Technology, Amity University, Noida, Uttar Pradesh, India,

Pawan Singh, Amity Institute of Information Technology, Amity University, Noida, Uttar Pradesh India.

Lavanya Sharma, Amity Institute of Information Technology, Amity University, Noida, Uttar Pradesh, India. customize the perception of view of the world [ 3,4$]$.

The field of AR has been introduced in the past few years yet the advancement in a previous couple of years has been exceptionally innovative. To achieve and execute AR technology, there are basically three things required i.e., Display to combine virtual $3 \mathrm{~d}$ objects to the real world, Trackers to locate your positioning with the help of gesture movements and the third component is hardware's and software's used for interaction. And also, virtual objects must be modeled in real-time environment for the better experience of the user. Augmented reality is accessible at any time and at any place if you have just a smartphone, Head Mounted Display or a PC. Augmented reality (AR) act as a platform for sharing information with the real world $[4,6]$. It changes the fact that how can we learn, how can we work and even how can we think.

The motivation behind any innovation is to improve everyone's life as shown in Fig.1.

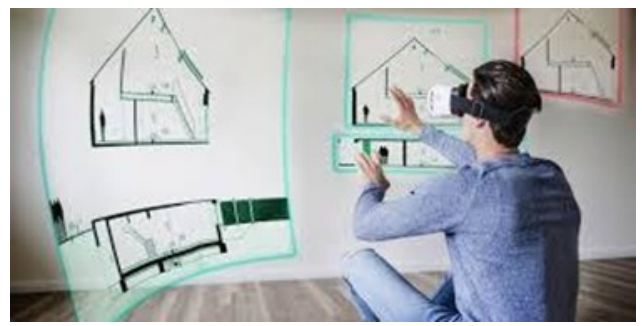

Fig.1. Future of Augmented Reality [13]

This paper is categorized into six section. Section 1, deals with introductory part of Augmented Reality, where as in section 2, is related work. Section 3 deals with history and evolution of Augmented Reality. In the next section 4 \& 5 Applications and challenges of Augmented Reality is discussed. In section 6 current solutions to AR problems are provided. In the last conclusion of the work is discussed.

\section{RELATED WORK}

A. Dünser et.al. [1] discussed about the user-based evaluation techniques used in Augmented reality and also provided some achievable opportunities for the future. M. Bulearca et.al.[2] discussed about the ways in which Augmented reality is beneficial for the marketing industry in a long run and described how it can satisfy the customer needs.

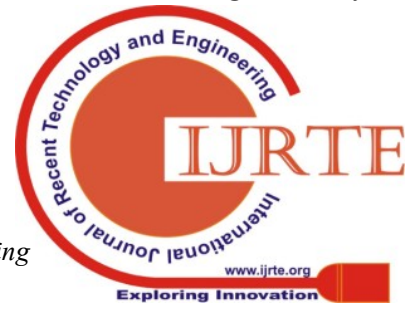


K. Lee [3] discussed about the ways to be educated in modern ways with the help of Augmented Reality and also described how AR can impact the future of learning. E. Zhu et.al. [4] discussed current condition of AR regarding user acceptance, AR application which had been developed and the impact of AR on the advancement of abilities in medical and health sector. R. Hammady [5] discussed about the Augmented Reality effectiveness and provided the ways in which it can use as a way communication in museums. Besides, this article also provided new ideas of increasing user perception by combining AR and games in museum D. Harborth [6] demonstrated that current exploration in AR is underrepresented in terms of technical view and also discussed about modification AR in gaming field. Ryosuke Umeda et.al [7] demonstrated a medical training overlays in the beneficial use of medical area and also prepared $3 \mathrm{~d}$ objects to evaluate AR platform. D. Chatzopoulous et.al.,[8] discussed that improvement in mobile technology like build in cameras, sensor, cloud computing has made AR convenience on smart-phones. T. Williams et.al.[9] discussed the ways in which the combination of Virtual. Mixed and Augmented reality enhance the interaction of human and robots and also provided the best practices for design for these interactions. K. Kim [10] discussed about the researches and trends from the last decade and also offered further observations for the future. L. Berkemeir et.al.,[11] discussed about the development of glass and provided enough solution for digital innovation in AR. V. Interrante et.al,[12] discussed the current state of AR and VR and how they can affect the future in a whole new way.

\section{HISTORY AND EVOLUTION OF AUGMENTED REALITY}

The first example of combination of physical and $3 \mathrm{~d}$ objects occurred in the 1960's when Ivan Sutherlands started the concept of virtual and augmented reality. In 1968 he created the first head mounted display known as Sword of Damocles which included the use of head tracking. And until the 1992 the field of augmented reality came to light by Boeing researcher Tom Caudell.[14] Advancement proceeded in 1994 when he presented augmented reality application for giving a doctor a chance to watch a baby specifically inside a pregnant patient.

In 1996, Hans Kaufmann and Stig[15] developed the first united and combined augmented reality system in which multiple users could share virtual objects in the same space. In 1997 Fenner's group [16] developed the first augmented reality system 'touring machine' at Colombia University, the touring machine uses a see-through head mounted display with GPS and orientation tracking delivering $3 \mathrm{~d}$ graphics.

In 1998, Bruce Thomas and Wayne Piekarski[17] developed "this is not map in the hat" a platform for AR that delivered first outdoor AR game Quake, which places the user in the middle of a zombie attack in a real-life parking area. In 1999, Kato and Mark Billings released AR toolkit the first open source software platform for augmented reality.
It featured a $3 d$ tracking library and the availability of webcams which made AR toolkit most popular. After 2000, mobile computing began growing rapidly, this presented a whole new opportunity for augmented reality.

And in 2003, Daniel Wagner and Shmuel Stig[18] presented the first AR system running on personalizedl digital assistant. It took several years until 2008, the first truly usable tracking featured system on smart devices introduced and after that AR technology becomes more easily available to the users.

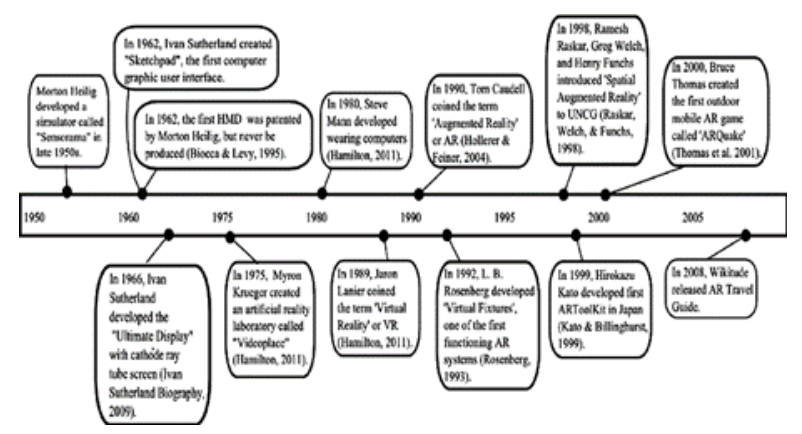

Fig.2. Evolution of Augmented Reality [19]

\section{APPLICATIONS OF AUGMENTED REALITY}

The Earlier, AR was likely to focus only on games but recent developments in AR technology also focused their attention in different fields like military, medical science, education, manufacturing and production industries, robotics and of course also in entertainment and gaming [10-16,21]. The application uses of AR in different fields make augmented reality a very productive innovation. The accompanying sub areas depicts latest researches and cover every application so far.

a. Medical: AR is the kind of innovation which is upgrading medical science towards more safety and proficiency. Microsoft HoloLens is one of the best examples of medical AR technology which is used for spinal surgery and it projects an overlay on the body of patients. And these overlays are used by surgeons to perform their operations. AR basically gives doctors or surgeons guidance to perform their tasks more effectively and efficiently with minimal risk. It provides interaction between two doctors who are miles away from each other and can discuss the surgeries. As well as it is also useful for the patients to acquire information for their treatments and preventions $[7,8,20]$. 


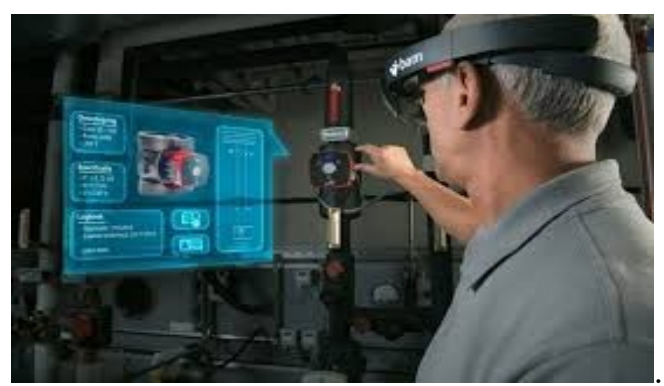

Fig.3. Microsoft HoloLens in Medical Imaging [21]

b. Military: Since military and warfare is constantly emerging with new technologies which help newest technologies like virtual and augmented reality to contribute its part in military. Following are the 3 ways to military augmentation reality [22].

- Tactical Augmented Reality: TAR also helps soldiers to provide the exact location of themselves and also give positions of the enemy forces. It works like night vision goggles but can work in the day as well.

- for army soldiers to prepare them physically and mentally ready for the real wars.

- Helmet Mounted AR Display: With the help of mounted displays, the soldiers can fight with each other virtually but in a realistic way. It provides overlays which contain different information of allied armies.

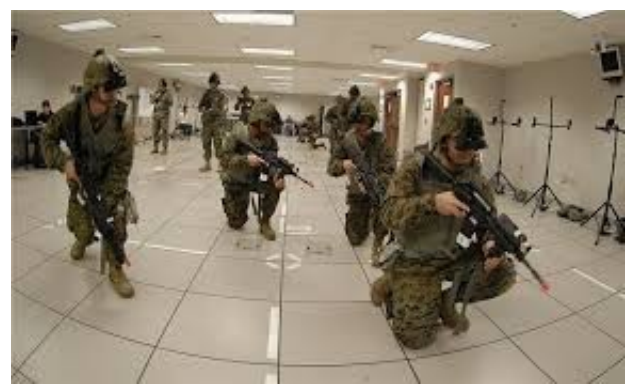

Fig.4. Military training using AR technology [23]

c. Education: With the help of mounted display, it can help the students to easily grab, process an learn the information more effectively. And of course, it made education more interesting, exciting and fun [24]. Augmented Education app provides modeling projects, $3 \mathrm{~d}$ overlays, and designs which help students to make their models to understand and learn animation and architectures. Augmented reality apps help to make boring lectures more interesting and more practical as an old saying "A picture is worth more than a thousand words" and AR is obviously more worth than a picture $[20,21]$.

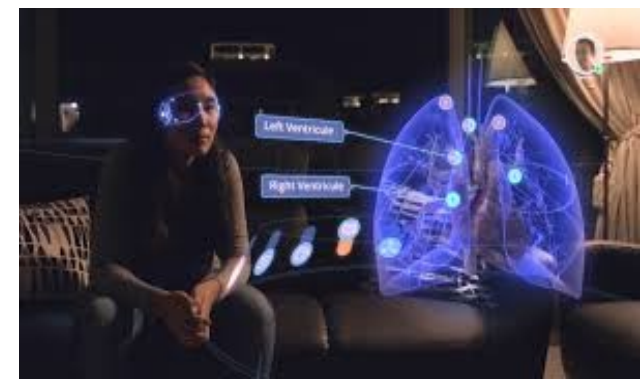

Fig.5. Head Mounted Display for easy learning [25]

d. Gaming and Entertainment: When we talk about the role of AR in animation and gaming, how can we forget the popular game "Pokémon Go". It's only because of this famous game, augmented reality comes again in the spotlight of people. In the gaming industry, AR became the first-runners as it helps the gamers to be in an imaginary world like fighting with zombies, aliens or capture fictional creators. Another famous game based on augmented reality is "Ingress" developed by Niantic studio which also becomes a massive hit. Other AR games are Temple Treasure Hunt, Army of Robots, Zombie Go, Sharks in the Park, Night Terrors, Beer Pong AR and many more [26]. With the application of augmented reality in the gaming and entertainment industry, gamers want to be a part of the game and with this desire to be included in-game, the game experience gets enhanced.

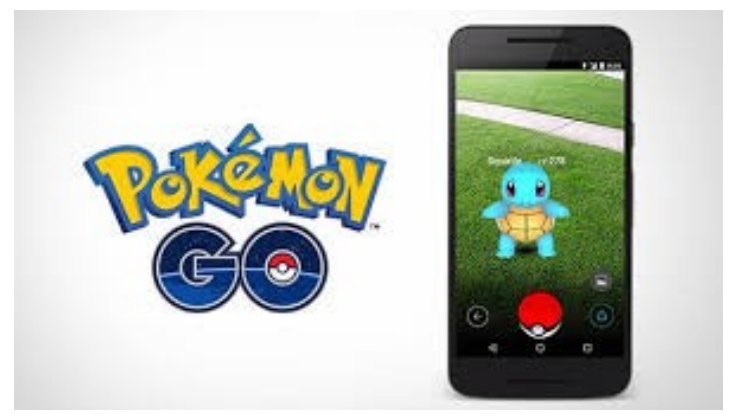

Fig.6. Game Pokémon Go [27]

e. Manufacturing and Production Industries:

Augmented reality helps to give a clear understanding and also to learn quickly. Introducing $\mathrm{AR}$ to production and manufacturing industries makes it easier to do more with even fewer efforts. And also saves human resources, resolves the problem faster with less risk. Following are some examples of popular industries which applies AR in their field [28]: 
- In design: Thyssenkrupp started using Microsoft HoloLens in their manufacturing industry that helps to interact with holograms overlaying in the surface of the real world for designing home mobility.

- In assembly: Boeing which is an Aircraft manufacturing company google glass and skylight in wire assembling in jets which makes it less complex.

- In quality control: Porsche, an automobile manufacturing industry already uses AR for years and made their future success a reality

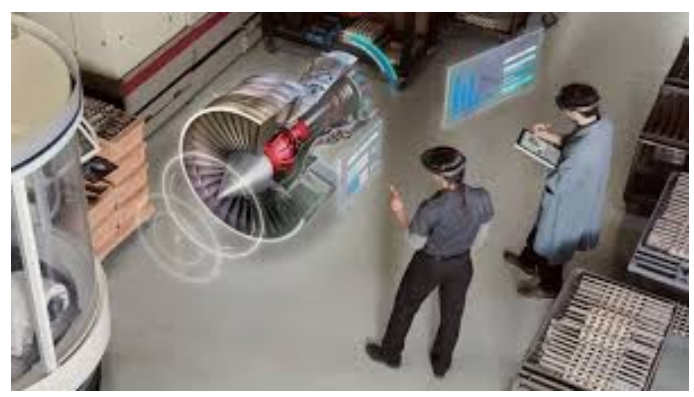

Fig.7. Use of AR in Automobile Industry [29]

f. Marketing and Advertising: As augmented reality catches eyes of everyone in the past few years, marketing and advertising industries also admitted as an expressive innovation of connecting customers and engage users. With AR it becomes possible for an E-Commerce website to allow their customers to check and try products virtually and then buy it after checking how the clothing items fit and how it looks [20,22]. This facility has been accomplished by companies like Lego and IKEA, where you can scan the products and check how it would fit you or into your home.

The concept of augmented reality also becomes a tool of storytelling medium for advertising your products as only then customers will find it easy to understand and will have a better experience, like explaining the features of products. Timberland also created a virtual fitting room in 2014 based on the concept on AR, in which shoppers can see an image of their face on the model body and try different outfits and can see what looks better [30].

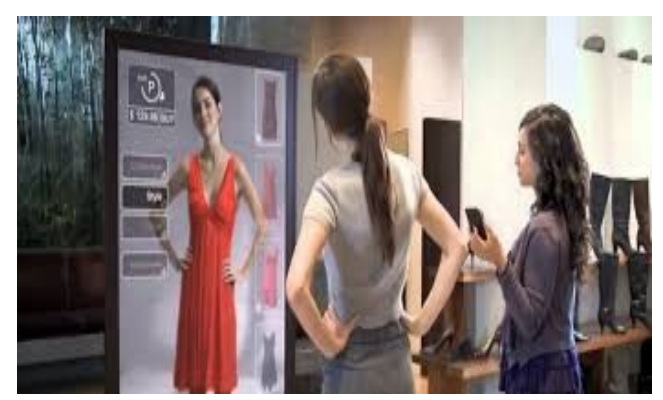

Fig.8. Virtual Fitting Room [31]

\section{CHALLENGES IN AUGMENTED REALITY}

1. Public acceptance: However, the augmented reality is slowly emerging and evolving in the last few years but there is always a hindrance when it comes to accepting this technology from people worldwide. There is a mild acceptance from the public because this technology is not believed useful for the long term because of poor quality and low standards designs of AR applications [32].

2. Poor quality of content: Except in gaming industries, $\mathrm{AR}$ applications is not having very effective content rather than it has only some simple non-tricky contents. Poor quality is the biggest reason why AR is facing certain issues when it comes to acceptance by people from all over the world. The reason behind this is maybe less expertise and developers in the AR field who can deliver a better experience quality [33].

3. Devices used in AR: There are many devices like cameras, screen motions, sensors, graphics, high internet connectivity, processors and many more which combines together to give us an experience of augmented reality world. But many other devices like HoloLens, google glass, AR headsets to feel a thrilling experience but these devices are costly and not easily available to the common public. Hence it is also the main challenges with augmented reality [34].

4. The possibility of physical harm: Augmented reality adds digital and virtual $3 \mathrm{~d}$ objects in the real world and also because of that it takes away the attention from the real world. There is a significant possibility of harming yourself from surrounding nature of mother earth. So, it is also the reason which becomes an obstacle in the way of the success of AR [35].

5. Technical challenges: there are many technical problems like hardware, less expertise, people education and awareness, poor content which makes AR difficult to use and socially acceptable [36].

6.Unsatisfying experience: Augmented reality made a hype surrounding to everyone after virtual reality that everybody is accepting so much from it and because of that brings less experience. Even good AR apps fail to give the user a better and immersive experience [37].

\section{Current Solutions to AR Problems}

An We can improve equipment capabilities utilizing exponential smoothing procedure, improve camera execution by utilizing 2D QR and scanner tag markers and utilize huge milestones to defeat GPS issues until better arrangements emerge for these issues [26-30, 32,34]. 
1. Noteworthy items like Microsoft HoloLens can possibly enlarge this present reality and remove any exasperating visuals that adversely sway client experience [20-24].

2. Increased the truth is an approach to bust the idea of restricting the interface of substance offering a path to a progressively intuitive, drawing in and out of the container (truly) experience. Presently your whole environment can go about as the holder for substance, subsequently giving a new experience to its utilization $[23,28]$.

3. With regards to $A R$, a solid and responsive route for announcing unbound sellers that don't consent to AR wellbeing, protection, and security norms will go far in driving purchaser trust in cutting edge AR items. And this can help in taking feedback from the AR users for further advancements in the future $[28,29]$.

4. Set up a kind of AR administering body that would assess, discussion and afterward distribute guidelines for designers to pursue. Alongside this, build up an incorporated advanced administration AR that groups public, private and business spaces $[30,35]$.

5. Perceiving dangers to purchaser security and protection is just the initial step to settling long haul vulnerabilities that quickly rising new innovations as AR make [32,37, 38-40].

\section{CONCLUSION}

In this paper, we provide a brief overview of Augmented Reality and its real-time applications in various areas such as education, medical, gaming, marketing, and many more. The main aim of this work is to study the uses of AR, some of the recent advancements of Augmented reality from the last few years. This paper also presents and discuss various challenging issues faced by $\mathrm{AR}$ as well as provides some current solutions and observations. As a whole, it can be concluded that $\mathrm{AR}$ is one of the technologies which can enhance the lives in modern ways and it can become the ubiquitous innovation in coming future.

\section{REFERENCES}

1. Dünser, R. Grasset and M. Billinghurst, "A Survey of Evaluation Techniques Used in Augmented Reality Studies," Human Interface Technology Laboratory New Zealand, 2008

2. M. Bulearca and D. Tamarjan, "Augmented Reality: A Sustainable Marketing Tool?" Economics of the Romanian Academy Bournemouth University, Vol.2, No. 2, 2010

3. K. Lee, "Augmented Reality in Education and Training," University of Northern Colorado, Vol. 56, No.2, 2012

4. E. Zhu et.al., "Augmented reality in healthcare education: an integrative review," Hubei University, China, 2014

5. R. Hammady, M. Ma and N. Temple, "Augmented Reality and Gamification in Heritage museums," University of Huddersfield, Huddersfield, UK, 2016

6. D. Harborth, "Augmented Reality in Information Systems Research: A Systematic Literature Review," Twenty-third Americas Conference on Information Systems, Boston, 2017

7. R. Umeda et.al., "A medical training system using augmented reality," Okinawa, Japan, 2017

8. D. Chatzopoulous et.al., "Mobile Augmented Reality Survey: From Where We Are to Where We Go," The Hong Kong University of Science and Technology, Hong Kong, Vol. 5, IEEE access, 2017

9. T. Williams et.al., "Virtual, Augmented, and Mixed Reality for Human-Robot Interaction," HRI'18 Companion, , Chicago, IL, USA, 2018

10. K. Kim et.al., "Revisiting Trends in Augmented Reality Research: A Review of the 2nd Decade of ISMAR (2008-2017)," Vol.24, 2018

11. L. Berkemeir et.al., "Engineering of Augmented Reality-Based Systems," Osnabruck University, Vol. 61, No, 67, 2019

12. V. Interrante et.al, "Virtual and Augmented Reality," University of California, Santa Barbara, Vol. 38, Issue 2, 2018

13. Future of Augmented Reality. Available at: https://encrypted-tbn0.gstatic.com/images?q=tbn:ANd9GcS 3UxNFLmq FTPEqns6Gc9Nppyb8pfv17tfO95gBEVtblxt5sdolA [accessed on 06march-2019]

14. http://sevenmediainc.com/the-history-of-augmented-reality/ [accesed on 06-march-2019]

15. https://vydia.com/evolution-augmented-reality/ 06-march-2019]

16. https://hcipioneers.wordpress.com/portfolio/feiner-steve/ [accessed on 06 -march-2019]

17. https://ultimatehistoryvideogames.jimdo.com/arquake/ [accessed on 06-march 2019]

18. https://medium.com/@argoproject/a-brief-history-of-augmented-reality-in fographic-af040a4fd86f [accessed on 06-march-2019]

19. Evolution of Augmented Reality. Available at https://www.researchgate.net/profile/Gallayanee_Yaoyuneyong/publicati on/228841030/figure/fig2/AS:300775898140673@1448721970472/Hi story-of-AR-a-brief-timeline.png [accessed on 09 -march-2019]

20. https://www.archer-soft.com/en/blog/how-augmented-reality-used-medici ne [accessed on 09-march-2019]

21. Microsoft HoloLens in Medical Imaging. Available at: https:/encrypted-tbn0.gstatic.com/images?q=tbn:ANd9GcTD9dAH2nYE IzZmXsACKVXw 4lgW3v0-1BRtI1154qqZKKD0o2L [accessed on 09-march-2019]

22. Augmented Reality in Defence Available at: https://jasoren.com/augmented-reality-military/ $\quad$ [accessed on 09-march-2019]

23. Military training using AR technology. Available at: https://encryptedbn0.gstatic.com/images?q=tbn:ANd9GcSeV3htqpAGeMsbZUIbjKjuUsH U_PYn4cz0azdUOWow-j9-A-Ie [accessed on 09-march-2019]

24. Augmented Reality in Education. Available at $\underline{\text { https://elearningindustry.com/augmented-reality-in-education-impact }}$ [accessed on 09-march-2019]

25. Head Mounted Display for easy learning. Available at https://encrypted-tbn0.gstatic.com/images?q=tbn:ANd9GcTPbMRxkqQ2 DMhtaJdJ0M59- 5wiecMzVK05y9foOiyi5Q4uSSoEtg [accessed on 10-march-2019]

26. Augmented Reality in Entertainment. Available at: https://augray.com/blog/augmented-reality-entertainment/ [accessed on 10- march-2019]

27. Game Pokemon Go. Available at: https:/encryptedtbn0.gstatic.com/images?q=tbn:ANd9GcRRVHTUgmtOicyOJyPm8VeR osZ3mYUveQJK63vgS034 KeAHoUR-hQ [accessed on 11-march-2019]

28. Augmented Reality in Industries. Available at https://dzone.com/articles/using-augmented-reality-in-manufacturing-indu stry [accessed on 10-march-2019]

29. Use of AR in Automobile Industry. Available at: https://encryptedtbn0.gstatic.com/images?q=tbn:ANd9GcSo4_PmYhuisLBM2G_PSuIa5 HAOI0UVqaJH3uhu3HDuwVG0HkjQxA [accessed on 11-march-2019]

30. Augmented Reality in Advertising media. Available at: https://rubygarage.org/blog/augmented-reality-in-advertising [accessed on 11-march-2019]

31. Virtual Fitting Room. Available at: https://encrypted-tbn0.gstatic.com/images?q=tbn:ANd9GcSuhWCOppsY rqE7uHoHz5retrCsgRjI x7sYokkjqW0GvgABJpU [accessed on 11-march-2019]

32. Augmented Reality challenges. Available at https://www.upwork.com/hiring/for-clients/biggest-challenges-augmented -reality/ [accessed on 12-march-2019]

33. Augmented Reality challenges. Available at https://www.weforum.org/agenda/2017/09/augmented-and-virtual-reality -will-change-how-we-create-and-consume-and-bring-new-risks/ [accessed on 12-march-2019]

34. Augmented Reality challenges. Available at: https://documoto.com/problem-with-augmented-reality/ [accessed on 12-march-2019]. 


\section{Recent Advancements of Augmented Reality in Real Time Applications}

35. Augmented Reality challenges. Available at https://www.csoonline.com/article/3101644/real-world-risks-in-an-augme nted-reality.html [accessed on 12-march-2019]

36. Augmented Reality challenges. Available at: https://datafloq.com/read/4-technical-challenges-ar-vr-need-to-solve/4148 [accessed on 12-march-2019]

37. Augmented Reality challenges. Available at: https://becominghuman.ai/six-ethical-problems-for-augmented-reality-6a8 dad27122 [accessed on 12- march-2019]

38. L.Sharma, N.Lohan, “ Internet of Things with Object detection: Challenges, Applications, and Solutions", Handbook of Research on Big Data and the IoT, IGI Global, pp. 89-100, March 2019.

39. L. Sharma, D. Yadav, A. Singh, "Fisher's linear discriminant ratio based threshold for moving human detection in thermal video", Infrared Physics \& Technology, Elsevier, vol. 78, pp. 118-128, Sept. 2016.

40. L. Sharma, D. Yadav, "Histogram-based adaptive learning for background modelling: moving object detection in video surveillance", International Journal of Telemedicine and Clinical Practices, Inderscience, vol. 2, no. 1, pp. 74-92, 2017.

41. Lavanya Sharma, Nirvikar Lohan, "Performance analysis of moving object detection using BGS techniques in visual surveillance", International Journal of Spatio- Temporal Data Science, Vol.1 No.1, pp.22 -53 , Jan. 2019

\section{AUTHORS PROFILE}

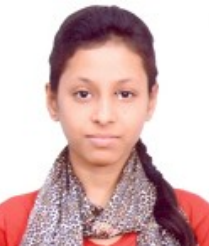

Gauri Jha is an BCA graduate in the field of information technology form Amity University. She is a recipient of several prestigious awards during academic career. She had worked in KR Network Cloud Technologies Pvt. Limited. She also developed an android application named Doconsult. She has adequate knowledge of different computer related programming language. Her current research interest includes Artificial intelligence

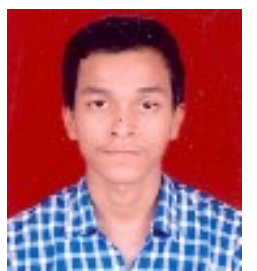

Pawan Singh is an BCA graduate in the field of information technology. He is a recipient of several prestigious awards during academic career. He had worked in KR Network Cloud Technologies Pvt. Limited. He has adequate knowledge of different computer related programming language. His current research interests include Cyber Security and Artificial Intelligence.

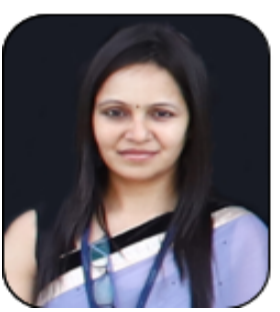

Dr. Lavanya Sharma is a $\mathrm{Ph} . \mathrm{D}$. graduate in the domain of Computer Vision at Uttarakhand Technical University (govt.), India and an assistant professor, Amity Institute of Information Technology at Amity University UP, Noida, India. She is an active nationally recognized researcher who produces dozens of papers in her field. She is an Editorial Member/ Reviewer of various journal of repute and active program committee member of various IEEE and Springer conferences also She is an active nationally recognized Computer Vision educator who has produced dozens of papers 